\title{
AGE, GENDER, SOCIO-ECONOMIC STATUS, ATTITUDES TOWARDS DRUG ABUSE AS DETERMINANTS OF DEVIANT BEHAVIOR AMONG UNDERGRADUATE STUDENTS
}

\author{
ROTIMI OGUNTAYO ${ }^{1}$, PAUL O. AJAO, KAYODE A. AKINTUNDE, OLUWAGBEMIGA A. \\ POPOOLA ${ }^{2}$, ADEREMI S. OPAYEMI ${ }^{3}$ \\ ${ }^{I}$ University of Ibadan, Ibadan, Nigeria \\ ${ }^{2}$ University of Ilorin, Ilorin, Nigeria \\ ${ }^{3}$ University of Winnipeg, Canada
}

(C) 2020 Rotimi Oguntayo, Paul O. Ajao, Kayode A. Akintunde, Oluwagbemiga A. Popoola, Aderemi S. Opayemi

This is an open access article distributed under the Creative Commons Attribution-NonCommercial-NoDerivs license (http://creativecommons.org/licenses/by-nc-nd/3.0/)

DOI: $10.1515 /$ eras-2020-0009

\begin{abstract}
Evidence from literature shows that deviant behavior is on high side among undergraduates in Nigeria whereas some certain psychosocial factors causing this phenomenon have not been fully explored. This study examined whether age, gender, socio-economic status and attitude towards drug abuse determine deviant behavior among the undergraduate students. It adopted ex-post facto design. Simple random sampling technique was used to sample 269 participants. The Prescription Drug Attitudes Questionnaire (PDAQ) and Deviant Behavior Variety Scale (DBVS) were used to gather data from the participants. T-test analysis and multiple regression were used to test the formulated hypotheses. The results revealed that age, monthly allowance and attitude towards drug abuse have significant joint prediction of deviant behavior $(\mathrm{R}=.358 \mathrm{R} 2=.128, \mathrm{~F}=10.594, \mathrm{p}<.05)$ while only attitude towards drug abuse independently predicted deviant behavior $(\mathrm{R}=.236, \mathrm{R} 2=.056 \mathrm{~F}=17.112 ; \mathrm{p}<.01)$. Also, there was a significant gender difference on deviant behavior [ $\mathrm{t}(293)=4.196, \mathrm{p}<.01]$, where male respondents scored high significantly $(\mathrm{M}=4.09, \mathrm{SD}=3.44)$ compared to female respondents $(\mathrm{M}=2.53, \mathrm{SD}=2.31)$ on deviant behavior. It is therefore recommended that policy makers in educational sector and the governing council of tertiary institutions need to create awareness on the debilitating effects of drugs on students' behavior, especially among males.
\end{abstract}

\section{Keywords}

Gender, Attitude towards drug abuse, Undergraduates, Deviant behavior

\section{Introduction}

In recent time, there have been growing trends in the act of deviant behavior among the undergraduates in Nigeria such as: cultism, examination malpractice, rape, embezzlement of students' association fund etc (Morakinyo \& Odejide, 2003; Popoola, Fowaraja, Oyeleke, Oguntayo, Fagbamila \& Opayemi, 2017). These previous studies posited that the deviance behavior has turned to an acute social problem, not only to the school authorities, members of family and the victims, but also to their schools and the society at large. For example, undergraduates' violence encourages school shooting, unrest, destruction of schools' properties and insecurity (Morakinyo, 2003). The imprint of deviance escalation in society has worsen moral degradation, prevalence in robbery acts and kidnapping in school environment.

Students' disruptive behavior has continued to derange school academic programmes or calendar to the extent that teachers are unable to cover the required contents of most courses and the school curriculum which consequently affects the quality of education in Nigeria 
university systems (Primack, Douglas \& Kraemer, 2010). These forms of unruly behavior in turn have resulted to poor academic performance of many adolescents in schools; in order for these set of students to achieve excellent results in external examinations, they retreat to examination malpractices (Primack et al., 2010). According to Adebiyi, Owaoje \& Asuzu (2008), deviance acts in learning environments especially in Nigeria tertiary institutions have reached the peak; it was discovered in the said study that, the factors perpetuating this menace are both social and psychological. In Gbadamosi (2003)'s study, it was confirmed that the high rate of deviant behavior reported among students in Kwara State has become public concern despite some government intervention, this calls for a research like this.

There are set of problems in contemporary society beyond demographics that trigger deviant behavior (Popoola et al., 2017). There is need for a study that will unravel these factors. Simanu (2015), reported that deviant behavior in schools includes: gang activity, fights, bullying, smoking, abuse of drugs, promiscuity, stealing, disruptive behavior, abseentism, drunkenness and other offences against the school rules and regulations. While Adebiyi et al., (2008), claimed that deviant behavior is posing a serious threat to learning in most academic environments, some abnormal acts in school are charged by bullying, harassment, insubordination and being violent to staff and co-students, sexual assaults, smoking and weapon carrying. These set of behaviors are detrimental to students and inhabitants in such environment. Studies conducted on deviant behavior in Nigerian schools showed that breaking of rule and regulations are persistent on the proportion of the sampled respondents (Wachira, 2001; Abdullahi, 2006). In addition, research conducted by Mwiria (1995) and Wachira (2001) revealed that, the most prominent factors leading to the prevalence of deviant behavior are failure in the part of community leaders to institute programs that will instill discipline in children, inadequate parental supervision and children exposure to aggression in the mass and social media. It was also revealed by Duffin and Taylor (2008) that specific style of parenting could also be associated with emergence of deviant behavior in school children. According to Jacob \& Adegboyega (2017), students get involved in deviant behavior due to unfavorable academic performance, teacher's negative attitude to work, illiteracy of parents, problems from home or school, accessibility to illicit drugs among others.

The incidence and pervasiveness of drug abuse and misuse have been a common phenomenon escalating in almost every angle around the world and have been a course of concern to family, schools, government and the society in recent times among undergraduates (Awosiyan \& Idoko, 2012). A drug refers to a substance that through its chemical actions could bring about a change in human biological function (Okoye, 2001; United Nations Organizations on Drug Council, 2005). Abuse of drug is the use of drugs to the level that interferes with persons' social functioning, biological state and health status (Abdulahi, 2009). The use and abuse of drugs by students have turned to become one of the perturbing health associated phenomena in Nigeria and some other countries around the globe (National Drug Law Enforcement Agency, 1997). Students of tertiary institutions abusing drugs also experience problems of interaction and engaging in the form of behavior that might affect them and the people that surround them. And these interactional problem and negative actions are encountered both inside their immediate family and the society at large (Hoffman, 1993).

Drug use and deviance are related in diverse ways; early antisocial behavior, problems in school, poor family relationships, drug-using friends and rebelliousness; though overall prevalence and classification of drug use differ by nations, for instance inhalants are recurrently utilized at high degrees (31\%-100\%) by street gangs, and youths in situations like school setting (Ayaya \& Esamai, 2001; Bal et al., 2010; Elkoussi \& Bakheet, 2011). Research posits that drugs use interact with the individuals' social life. For instance, substance use disorders can predispose youths to personal problem and anti-social behaviors (Lynskey, Degenhardt, 
Morley, Stockings, Patton \& Weier, 2016). This makes it to become a concern not only to the relatives and associates of the doer but the community at large (White, 2014). Positive disposition to drug use is one of the most common issues found among college and tertiary institution students of all ages (Han, Compton, Blanco \& Colpe, 2017). The current study focusses on the undergraduate population as they are mostly referred to as the future of any nation, of their parents and loved ones, but not only that, they are the age grade that determines the growth and development of their society in matter of positive changes economically, psychologically and socially, and hence this turns out to make young ones at a higher risk of using drugs (Lynskey et al., 2016). The present study is unique and necessary because with much and more open ways deviance acts the more the distressful lifestyles of such country lives are. Gender and drug use have also been discovered to determine deviance or non-conformity (Moreno \& Whitehill, 2014). A study has shown the negative role and influence of drugs, attitudes towards drug use and drug users on disobedience (Montagne, 2011). A study has compared substance use to individuals who have negative dispositions to drugs, the respondents were more of obedience than deviance (Primack et al., 2010).

Some empirical studies have emphasized on the positive relationship between harder drug use and deviance (Jacob et al., 2017). Attitude towards drug abuse in the recent time has become a major concern to the entire Nigerian society, especially among undergraduates considering the campus unrest. For instance, a study has shown that, among adolescents abusing drug, favorable impression towards substance use has influence on subsequent crimes or violence (rape and aggravated assault) (Elliott et al., 1989; Jacob et al., 2017). According to Jacob et al., (2017), deviant behaviors in the University system are not basically an outcome of drug abuse but there exist other factors that pose threat to students' survival in schools and the society at large, especially the socio-economic factors ranging from age, gender, and student's exposure to destructive acts.

Youth from low socio-economic status can suffer negative effects of history of parents' drug use; for instance, a study put it that one with positive parent history of drugs use from low background has increased risky deviance acts compared to the one with no adverse parenting drug-dependent history (Witorsch \& Witorsch, 2000). This does not mean that drug-dependent individuals are necessarily poor parents. More so, a study has identified that younger ones of drug abuse parents have more tendency to indulge in risky deviance behaviors than other young youths (Street, Harrington, Chiang, Cairns \& Ellis, 2004). Considering how the previous literature has been growing, the need to explore whether age, gender, socio-economic status and attitudes of the undergraduates towards drug abuse could determine the level at which students could engage in deviant behaviors is necessary. Based on the gaps and controversial results in the past reviewed literature, attitudes towards drug abuse and gender were investigated as probable factors that could determine deviant behavior among the students. This study seeks to examine whether gender and attitude towards drug abuse could determine deviant behavior among the undergraduate students.

\section{Hypotheses}

i. Male respondents will significantly score higher on deviant behavior than female respondents.

ii. Age, monthly allowance and attitudes towards drug abuse will significantly jointly and independently predict deviant behavior. 


\section{Method}

\section{Design}

The research design used for this study was ex-post facto design. This is so because the independent variable cannot be manipulated, and the dependent variable was measured continuously. The independent variable is attitude towards drug abuse while dependent variable is deviant behavior. These variables were measured through the administration of questionnaires.

\section{Sampling Technique}

The population of the study were undergraduates of University of Ilorin. The sampling technique utilized was simple randomization. Participants were randomly selected using even and odd number, those who picked even number were strictly considered for the study and only the students of university of Ilorin were involved.

\section{Participants}

The participants were undergraduates in the Faculties of Social and Management Sciences of University of Ilorin in Kwara state. It only involved 296 undergraduates above 18 years of age. Participants gender; 168(66.2\%) were males and $110(33.8 \%)$ were females. The Christian participants were of 150(50.7\%) and Muslims were 146(49.3\%). As per their tribe and ethnicity, Yoruba respondents were 101(34.1\%), Hausas were 76(25.7\%), Igbos were $69(23.3 \%)$ and other tribes from minority groups in Nigeria were 50(16.9\%). Considering their departments in the faculties of social and management sciences; those from Political Science were 58(19.6\%), Marketing 33(11.1\%), Sociology 40(13.5\%), Public Administration 41(13.9\%), Psychology 20 (6.8\%), Social Works 32(10.8\%), Geography 19(6.4\%), Business Administration 25(8.4\%) and Industrial and Labor Relations were 28(9.5\%).

\section{Instrument}

This section comprises of socio-demographic data of the participants, such as their gender, age, religion, department and tribe; the psychological instruments used were:

\section{The Prescription Drug Attitudes Questionnaire (PDAQ)}

PDAQ is an inventory designed by Bodenlos, Malordy, Mayrsohn, Mistler \& Noonan (2014) to assess attitudes towards drug use. The questionnaire was piloted for testing on 50 participants who are students and the results from qualitative analysis were used to generate the items utilized and the scale was revised later by the same authors. In conclusive stage, items were criticized by an expert in the areas of forensic psychology and further amended. The Cronbach's Alpha recorded for the overall subscales was .94, the first factor loading was .92 and the second factor loading was .89, while the final analysis retained a set of 26-items, respondents guided to tick the degree to which they either agreed or disagreed with each of the items using a Likert scale of 5-point, while $1=$ strongly disagree, disagree $=2,3=$ indicate indifference, agree $=4$ while strongly agree $=6$. Higher scores indicate positive disposition to drugs use.

\section{Deviant Behavior Varieties Scale (DBVS)}

The DBVS was developed by Sanches, Gouveia-Pereira, Marôco, Gomes \& Roncon (2016) to assess involvement in deviant behavior among youth. It is a 19-item scale with Cronbach $\alpha 0.83$. The reliability of the scale was investigated during the current study and 0.90 was achieved. It adopted a response Likert format of yes $=2$, don't know $=1$ or no $=0$. A participants' score is calculated by adding up the dichotomous raw sum on each respondent's 
answer. The overall scores range between 0 and 38, while scores between 12 to 22 indicate high, and 23 to 38 indicate higher scores DBVS mean that the person has tendency or probable history of delinquency and deviance or anti-social behavior. It takes 5 to 10 minutes to complete this questionnaire.

\section{Procedure}

When the questionnaire was to be distributed to each participant, a simple introductory discussion was conducted. Participants were exposed to the essence of the survey and they were asked in a polite manner to help filling the items in the questionnaire. Each participant was assured of confidentiality that their opinions are only needed for research purpose only (information about their opinions will not be divulged to a third party). Only those who signed the inform consent could participate. After gathering the data, it was then analyzed in order to fish out the information needed.

\section{Statistical Analysis}

Descriptive statistics was used to analyze the demographic data, t-test and regression analysis were used as inferential statistics to analyze the gathered data. All these were carried out using the Statistical Package for Social Sciences 21.0 (SPSS).

\section{Results}

The results revealed that age, monthly allowance and attitude towards drug abuse did predicted deviant behavior $(\mathrm{R}=.358 \mathrm{R} 2=.128, \mathrm{~F}=10.594, \mathrm{p}<.05)$; when combined with age, monthly allowance and attitude towards drug abuse accounted for $13 \%$ of the change observed in the measurement of deviant behavior. However, the remaining $88 \%$ can be attributed to other variables not considered in the study. Similarly, the analysis of independent prediction showed that monthly allowance $(\beta=.181, \mathrm{t}=3.258, \mathrm{p}<.05)$ and attitude towards drug abuse $(\beta=.194, \mathrm{t}=-$ $3.478, \mathrm{p}<.05)$ had significant independent prediction of deviant behavior, while age $(\beta=-.007$, $\mathrm{t}=-.118, \mathrm{p}>.05)$ did not independently predict deviant behavior significantly. Furthermore, it could conclude that, deviant behavior is determined by monthly allowance and attitude towards drug abuse, while age does not influence deviant behavior among the tested variables.

Table 1 Summary Showing Significant Prediction of Age, Monthly Allowance and Attitude towards Drug Abuse of Deviant Behavior Using Multiple Regression.

\begin{tabular}{lccccccc}
\hline Variables & $\mathrm{R}$ & $\mathrm{R}^{2}$ & $\mathrm{~F}$ & $\mathrm{Sig}$ & $\mathrm{Beta}$ & $\mathrm{t}$ & $\mathrm{P}$ \\
\hline Age & .358 & .128 & 10.594 & .000 & -.007 & -.118 & .906 \\
Monthly allowance & & & & & .181 & 3.258 & .001 \\
Attitudes towards drug abuse & & & & & .194 & 3.478 & .001
\end{tabular}

Dependent variable: Deviant behavior

Table 2 presents results of gender differences on deviant behavior. There was significant difference in the score of deviant behavior $[\mathrm{t}(293)=4.196, \mathrm{p}<.01$. Furthermore, male respondents $(\mathrm{M}=4.09, \mathrm{SD}=3.44)$ differ significantly compared to female respondents $(\mathrm{M}=2.53$, $\mathrm{SD}=2.31$ ). The result implies that gender significantly influences deviant behavior among the respondents. The hypothesis is thus accepted. 
Table 2 of t-Test Summary Table Showing Gender Difference Between Respondents with Male and Female Level of Gender on Deviant Behaviour

\begin{tabular}{llcccccc}
\hline & Gender & $\mathbf{N}$ & $\bar{X}$ & Std & Df & T & p \\
\hline Deviant behavior & Male & 185 & 4.09 & 3.44 & & & \\
& Female & 110 & 2.53 & 2.31 & & & \\
& & & & & & & \\
\hline
\end{tabular}

\section{Discussion}

The finding of the previous research seems to be in line with present study in the selected area. From the first hypothesis that stated that age, monthly allowance and attitude towards drug abuse will significantly jointly and independently influence deviant behavior, the result statement was confirmed when age, monthly allowance and attitudes towards drug abuse jointly accounted for $13 \%$ of the change observed in the measurement of deviant behavior. This result is similar to other previous studies (Arnett, 1990; Zuckerman, 2000; Cook, Buehler, \& Henson, 2009; Bryant \& Zimmerman, 2002); in these researches it was found that student participation in deviant (risky) behavior was associated to some of student characteristics such as age, ethnic group, sex, socioeconomic status and school performance. This revealed that the collective presence of different socio-demographic factors has significant joint influence on deviant behavior. Also, attitude towards drug abuse did significantly predicted deviant behavior among undergraduates. This result confirms the findings of Israel and Nyoho (2015) who reported that students are prone to various degree of violence in schools due to positive disposition to drug use. The research finding is in line with that of Ellickson and MaGuigan (1996) who posited that drugs are in many cases linked to deviant behavior such as violence among adolescents and young adults. This is linked up with the findings of Uwaifor (2003), who observed that drug abuse correlates with level of truancy and cases of low cognitive ability among students.

Hypothesis two stated that male respondents will significantly score higher on deviant behavior than female respondents. The result revealed that gender has significant difference in the scores of deviant behaviors among the respondents. Males significantly scored higher on deviant behavior compare to female respondents. This result is in line with Rudasill, Reio, Stipanovic \& Taylor (2010) findings. This implies that gender significantly influences deviant behavior. In African cultural expectation, boys are expected to be assertive, strong and even sometimes stubborn, this role play and history of inoculation may or probably makes males to be much more susceptible to deviance acts compared to females who are expected to be cool headed, patient and weak, as Bible refers to them as "weaker vessel".

\section{Conclusion}

Looking at the findings of this study, it is concluded based on the strength of the findings, that there is an epitome of the influence of the kind of attitude that undergraduate has towards drug abuse on the deviant acts. It is a note worthwhile that undergraduate's drugs dispositions would determine the types of behavior they will be exhibiting both in the present and in the future. The findings also revealed that there is gender difference on deviant behavior, though collective presence of demographic variables has significant influence on deviant behavior. This implies that demographic variables such as gender, age and monthly allowance also affect the form of behavior that undergraduates exhibit.

Results gotten on gender in this study made us realize that male undergraduates are prone to deviant acts more than female counterparts, this could probably be that some activities 
being embarked on by some males are correlated with deviant acts. It was also noted that the allowance being given to the undergraduates also make them to be susceptible to deviant acts. As it's been said that "an idle hands are devil's workshop", so, undergraduates that falls within this range may find it difficult to restrict themselves from deviant acts because of either excessive financial stance or low income. It can also be inferred that the sampled undergraduates can be easily pressured to commit atrocities under the influence of drug use.

\section{Recommendations}

Based on the discoveries of this study, the following recommendations are reached thus:

i. The school management should prioritize assessment for drug disposition both on the new intakes and the old students; orientation program, as well seminars should be organized periodically to dissuade positive attitudes towards drugs through proper counselling among the affected students.

ii. Government and stakeholders at all levels should make the inclusion of drug and drug abuse course mandatory for all undergraduates to prevent the abuse of the substance through the knowledge gained.

iii. Researchers in the field of psychology and other allied disciplines such as sociology, counselling and social work units should take the matter as urgency so that their contributions would help to make a stronger awareness on the menace of deviant behavior and its debilitating effects on the undergraduates.

\section{Conflict of Interest}

None was declared.

\section{REFERENCES}

Abdullahi, M.I. (2006). Control of drug abuse and some aspects of tobacco smoking: A societal challenge. Isa Kaita journal, 2(2), 7-20.

Adebiyi, A., Owaoje, O. \& Asuzu, M. (2008). Relationships as determinants of substance use amongst street children in local government area in south-western Nigeria. South African Family Practice. 50(5):47-47.

Arnett, J. (1990). Drunk driving, sensation seeking, and egocentrism among adolescents. Personality and Individual Differences, 11, 541-546.

Ayaya, S.O., \& Esamai, F.O. (2001). Health problems of street children in Eldoret, Kenya. East Africa Medical Journal, 78(12):624-9.

Awosiyan, K. \& Idoko, C. (2012). Mass failure in public examination: Causes, challenges and solution to how to pass WAEC. NECO JAMB. Retrieved from http://www.sunday.tribune.com.ng/index.php/education/40618-mass-failure-in-public-examinationsthecauses-challenges-and-solutions-how-to-pass-wassceneco-jamb-candidates-need-to-be-more-careful.

Bal, B., Mitra, R., Mallick AH, Chakraborti S, Sarkar K. (2010). Nontobacco substance use, sexual abuse, HIV, and sexually transmitted infection among street children in Kolkata, India. Substance Use \& Misuse, 45(10): 16, 68-82.

Bryant, A. L., \& Zimmerman, M. A. (2002). Examining the effects of academic beliefs and behaviors on changes in substance use among urban adolescents. Journal of Educational Psychology, 94, 621-637.

Cook, E. C., Buehler, C., \& Henson, R. (2009). Parents and peers as social influences to determine antisocial behavior. Journal of Youth \&Adolescence, 38(9), 1240-1252

Duffin, M. \& Taylor E., (2008). Gangs and Schools: InteriTheReport. An interim report for the NAS/UWT, Leicester, Perpetuity Research and Consultancy International Ltd

Ellickson, P.L., Saner, H. \& McGuigan, K.A. (1996). Profiles of violent youth, substance use, and other concurrent problems. Am J Public Health, 86: 985-991

Elliott. D., Huizinga, D., \& Menard. S. (1989). Multiple problem youth: Delinquency, substance use, and mental health problems. New York: Springer-Verlag. 
Rotimi Oguntayo, Paul O. Ajao, Kayode A. Akintunde, Oluwagbemiga A. Popoola, Aderemi S. Opayemi, Age, Gender, Socio-Economic Status, Attitudes towards Drug Abuse

DOI: 10.1515/eras-2020-0009

Elkoussi, A., \& Bakheet, S. (2011). Volatile substance misuse among street children in Upper Egypt. Subst Use Misuse, 46(1):35-9.

Gbadamosi, M.O. (2003). Pattern and causes of deviant behaviours among secondary school students as perceived by teachers in Ilorin metropolis. Unpublished M.Ed thesis in the Department of Counsellor Education University of Ilorin.

Han, B., Compton, W. M., Blanco, C., \& Colpe, L. J. (2017). Prevalence, treatment, and unmet treatment needs of US adults with mental health and substance use disorders. Health affairs, 36(10), 1739-1747.

Hoffman, J.P. (1993). Exploring the direct and indirect family effects on adolescent drug use. Journal of Drug Issues, 23:535-557.

Israel, E. \& Nyoho, E. (2015). Illicit drug use and emotional behaviour of senior secondary Students in public schools in akwa ibom state, Nigeria. International Journal of Education, Learning and Development, 4(1,) 52-59.

Jacob, O. A. \& Adegboyega L. O. (2017). Perceived Causes and Incidences of Deviant Behaviour Among Secondary School Students in Kwara State. TBU, Journal of Science, Technology \& Education (JOTE), 5(2), 11-22.

Moreno, M. A., \& Whitehill, J. M. (2014). Influence of social media on alcohol use in adolescents and young adults. Alcohol research: current reviews, 36(1), 91

Montagne, M. (2011). Drugs and the Media: An Introduction, 849-851. Retrieved From https://doi.org/10.3109/10826084.2011.570609

Mwiria, D. (1995). Deviant sexual behaviour. Journal of Research on Adolescence, 6(2), 9-10

Morakinyo, J., \& Odejide, A.O. (2003). A community-based study of patterns of psychoactive Substance Use among street children in a local government area of Nigeria. Drug and Alcohol Dependence, 71(2):109116.

NDLEA. (1997). Drug date collection and research, Lagos: Drug Demand and Reduction Unit National Drug Law Enforcement Agency.

Okoye, N. N., (2001). The adolescents and hard drugs: A psychological concern in R.U.N, Prescription Drug Attitudes Questionnaire: Development and Validation. Psychology, 5, 1687-1693. Retrieved from http://www.scirp.org/journal/psych

Popoola, O.A, Faworaja, O.R., Oyeleke, J.T., Oguntayo R., Fagbamila, D.O.; \& Opayemi, A.S. (2017). Personality and Retaliation as Predictors of Criminal Behaviour Among Murder Suspects in Agodi Prison, Ibadan. African Journal for the Psychological Study of Social Issues, 20(3), 1-11

Rudasill, M. R., Thomas, G. J., Stipanovic, N. \& Taylor, J. E. (2010). A longitudinal study of student-teacher relationship quality, difficult temperament, and risky behavior from childhood to early adolescence. Educational Psychology, 2; 34-45.

Primack, B. A., Douglas, E. L., \& Kraemer, K. L. (2010). Exposure to cannabis in popular music and cannabis use among adolescents. Addiction, 105(3), 515-523. https://doi.org/10.1111/j.1360-0443.2009.02801.x

Sampson, Robert J., \& John, H. L. (1992). Crime and Deviance in the Life Course Annual Review of Sociology 18: 63-84. 1993.

Sanches, S., Gouveia-Pereira, M., Marôco, J., Gomes, H., \& Roncon, F. (2016). Deviant behavior variety scale: development and validation with a sample of Portuguese adolescents. Psicologia: Reflexão e Crítica, 29 (31), 1-8

Simanu, E.H. (2015). An Investigation into The Relationship Between School Leadership and Learners' Academic Performance at Four Secondary Schools in The Kavango Region, Namibia. A published M.Ed Thesis, Department of Education Policy Studies at Stellenbosch University, UNZA. Retrieved from https://scholar.sun.ac.za

Street, K., Harrington, J., Chiang, W., Cairns, P., \& Ellis, M. (2004). How great is the risk of abuse in infants born to drug-using mothers? Child: Care, Health and Development, 30(4), 325-330

Wachira, P. K., (2001). Factors leading to the influence of undesirable social behaviour among students in selected Nairobi secondary schools. Unpublished MEd. Project Report, Kenyatta University.

White, J. M., Gordon, J. R., \& Mimiaga, M. J. (2014). The role of substance use and mental health problems in medication adherence among HIV-infected MSM. LGBT health, 1(4), 319

Witorsch, R.J. \& Witorsch, P. (2000). Environmental tobacco smoke and respiratory health in children: a critical review and analysis of the literature from 1969 to 1998. Indoor and Built Environment, 9(5):246-264.

Uwaifor, A. N. (2003). Influence of Drug on Absorption of facts in infants. Unpublished B.Sc Project of University of Calabar. Nigeria. 
Rotimi Oguntayo, Paul O. Ajao, Kayode A. Akintunde, Oluwagbemiga A. Popoola, Aderemi S. Opayemi, Age, Gender, Socio-Economic Status, Attitudes towards Drug Abuse

DOI: 10.1515/eras-2020-0009

Zuckerman, M., \& Kuhlman, D. M. (2000). Personality and risk-taking: Common biosocial factors. Journal of Personality, 68(6), 999-1029. doi:10.1111/1467-6494.00124 